\title{
O léxico da cultura açucareira na construção do mundo atlântico: Madeira, Canárias, Cabo Verde, S. Tomé e Príncipe, Brasil, Venezuela e Colômbia
}

\author{
Naidea Nunes Nunes*
}

O léxico é a componente da língua que melhor expressa a realidade históricogeográfica, etnográfica e sociocultural de um povo, país, região, localidade ou comunidade linguística. Através do conhecimento das "palavras e coisas" da produção açucareira (termos e técnicas), podemos conhecer o património histórico, linguístico e cultural do açúcar de cana na construção do mundo atlântico. O estudo do léxico da cultura açucareira no Atlântico resultou na elaboração de um glossário comparativo desta terminologia histórica das ilhas do Atlântico Oriental e do Brasil (NunEs, 2002; 2003a) e, posteriormente, do glossário comparativo da atual terminologia açucareira do Atlântico (NunEs, 2010), incluindo a Venezuela e a Colômbia. A grande extensão geográfica da cultura açucareira, sobretudo na América Latina, mostra bem que nunca houve fronteiras históricas, geográficas, económicas, linguísticas e culturais para a expansão das técnicas e das palavras associadas às mobilidades humanas, nos processos de colonização portugueses e espanhóis. Vieira escreve que:

\begin{abstract}
A Madeira manteve uma posição relevante, por ter sido a primeira área do espaço atlântico a receber a nova cultura [açucareira]. E por isso foi aqui que se definiram os primeiros contornos desta realidade, que teve plena afirmação nas Antilhas e Brasil. Foi na Madeira que a cana-de-açúcar iniciou a diáspora atlântica. Aqui surgiram os primeiros contornos sociais (a escravatura), técnicos (engenho de água) e político-económicos (trilogia rural) que materializaram a civilização do açúcar (1996, p. 9-10).
\end{abstract}

O autor refere que a própria tradição de esculpir levadas fez com que "os madeirenses se tivessem transformado nos seus exímios construtores, levando a tecnologia a todo o lado onde se fixaram. Primeiro foi as Canárias e, depois, na América”. Acrescenta que esta perícia e engenho dos madeirenses estão evidenciados no pedido de Afonso de Albuquerque para que o rei lhe enviasse madeirenses que "cortavam as serras pera fazerem levadas, com que se regam as cannas de açú-

Doutora em Linguística Românica e professora auxiliar da Universidade da Madeira, Funchal, ilha da Madeira, Portugal. E-mail: naidean@staff.uma.pt 
car” (VIEIRA, 1996, p. 10). Pois, a irrigação era fundamental no cultivo da cana-deaçúcar, assim como a lenha era essencial para o fabrico do açúcar. Em Canaviais e açúcar no espaço insular Atlântico: questões de meio ambiente e técnica, Vieira reafirma que:

A Madeira surge, nos alvores do século XV, como a primeira experiência de ocupação em que se ensaiaram produtos, técnicas e estruturas institucionais [...] O arquipélago madeirense foi o centro de irradiação dos sustentáculos da nova sociedade e economia do mundo atlântico [...]. Daqui resultou para a Madeira o papel fundamental de difusão das culturas existentes na Europa e que tinham valor mercantil [...]. No traçado das rotas oceânicas situava-se o Mediterrâneo Atlântico com um papel primordial na manutenção e apoio à navegação atlântica (s.d., p. 2).

Foi neste contexto que a Madeira e as Canárias desempenharam um papel fundamental.

A cultura dos canaviais divulgou-se no espaço atlântico a partir dos arquipélagos do Atlântico oriental. Começou na Madeira, donde passou aos Açores, Canárias, Cabo Verde e São Tomé e Príncipe. Todavia não mereceu em todos a mesma importância, podendo-se definir apenas como ilhas do açúcar as da Madeira, Gran Canária, Tenerife, La Palma, La Gomera e S. Tomé. Nos Açores e em Cabo Verde a presença foi pouco significativa no século XVI (VIEIRA, s.d., p. 11-12).

No que se refere às Canárias, o autor diz ter sido uma das áreas açucareiras concorrentes da Madeira, estando o seu desenvolvimento inegavelmente ligado aos madeirenses. Nota que os incentivos à produção de canaviais nas ilhas de Gran Canária e de Tenerife fizeram com que muitos madeirenses deixassem a ilha e se fixassem nas Canárias (Vieira, 1987, p. 115). Quanto a Cabo Verde, Vieira (s.d., p. 15) menciona que a presença dos canaviais está documentada desde a segunda metade do século XV, com referência à produção de cana-de-açúcar em 1490 . A cultura terá começado na ilha de Santiago e, só depois, no século XVII, ter-se-á espalhado às ilhas de S. Nicolau, Brava, Maio, Boavista e Santo Antão, para fabrico de aguardente usada no comércio de escravos na costa africana, conforme informações de Carreira (1982) e de Lopes Filho (1995). Vieira acrescenta que foi em Santiago e em Santo Antão que a cultura açucareira encontrou melhores terrenos e adquiriu maior importância, referindo Frutuoso que, para a ilha de Santiago, indica "dá muito açúcar e fazem-se nela muito boas conservas, ainda que nada disto chega ao da ilha da Madeira" (s.d., p. 117). Hoje, o doce de papaia com mel de cana é muito importante na ilha de Santo Antão, sendo um dos muitos vestígios de conservação da tradição açucareira, como pudemos constatar in loco. Segundo Vieira (s.d., p. 8), as ilhas do Golfo da Guiné ofereciam melhores condições para a produção 
açucareira do que a da Madeira e as das Canárias, dado que o clima e o solo permitiam que as canas crescessem três vezes mais, sem precisarem de rega e fazendose duas colheitas por ano. O mesmo acontecia com a situação das ilhas do outro lado do oceano, no Caribe, com grande desenvolvimento dos canaviais a partir do século XVII. Posteriormente, a produção açucareira expandiu-se para as atuais Venezuela e Colômbia, entre outras regiões da América Latina. Em relação ao Brasil, Vieira (s.d., p. 29) afirma que o primeiro engenho construído por iniciativa da coroa portuguesa, em 1555, foi o de João Velosa, apontado como madeirense, referindo Magalhães (1953) e Gouveia (1987). Vieira (s.d., p. 15 e 30) acrescenta que as primeiras plantas de cana terão sido levadas da Madeira para o Brasil, dando conta que, em Pernambuco e na Baía, entre os oficiais (purgadores, carpinteiros, mestres) e proprietários ou senhores de engenho, havia forte presença madeirense.

No que se refere à atualidade, Vieira (s.d., p. 3) é de opinião que a poncha e o bolo de mel madeirenses é que mantêm a sobrevivência da cultura açucareira na ilha da Madeira. Nas Canárias, segundo o autor, a sua presença hoje ocorre apenas nas ilhas de Gran Canária e de La Palma. Nos Açores desapareceu para dar lugar à beterraba açucareira, enquanto em Cabo Verde subsiste em algumas ilhas (Santiago, Santo Antão e S. Nicolau), por força do uso da aguardente, chamada grog, e de bebidas típicas como bandoi e ponche, conforme Lopes Filho (1997, p. 212). Em S. Tomé e Príncipe, depois de ter desaparecido, com as roças de café e de cacau, o cultivo da cana-de-açúcar foi reintroduzido pontualmente pelos imigrantes caboverdianos que levaram consigo a tradição açucareira do grog, do mel de cana e do doce de papaia, entre outros. Deste modo, a terminologia açucareira encontrada na ilha de S. Tomé é a mesma de Cabo Verde. Vieira conclui que "O açúcar é de todos os produtos que acompanharam a expansão europeia aquele que moldou, com maior relevo, o quotidiano das novas sociedades e economias que, em muitos casos, se afirmaram como resultado dele" (s.d., p. 3).

Depois deste percurso histórico-geográfico pelo mundo atlântico, veremos como o léxico açucareiro histórico e atual reflete, ainda hoje, as ligações linguísticas e culturais atlânticas da época da expansão portuguesa e do início das colonizações, principalmente das ilhas atlânticas e do Novo Mundo.

\section{O léxico da cultura açucareira na documentação histórica da Ma- deira e das Canárias}

\section{Técnicas e profissões da produção açucareira}

O estudo do léxico, no âmbito da História da Língua Portuguesa, através da documentação escrita que chegou até aos nossos dias sobre a cultura açucareira, complementa o trabalho já desenvolvido pelos historiadores. Se compararmos a terminologia histórica do açúcar, registada na documentação da Madeira e das Canárias dos séculos XV e XVI, utilizando fontes documentais que nos fornecem 
importantes informações sobre a produção açucareira da época, e procedermos à sua análise nestas duas regiões açucareiras, confirmamos a transplantação do vocabulário e das técnicas do açúcar da Madeira para as Canárias, onde encontramos muitos portuguesismos relacionados com esta atividade (PÉrez VIDAL, 1991). Viña Brito, Corrales e Corbella, a propósito desta importação, explicam que:

De Madeira no sollo llegaron a Canarias, en 1483, los primeros plantanos de caña y los oficiales que entendian de la construcción de ingenios y de la manufactura del azúcar, sino también la mayor parte de un vocabulário singular. Ese conjunto terminológico estaba compuesto por voces tradicionales, propias de la agricultura y por palabras de ascendencia árabe o mozárabe ligadas a la industria de la vid y del aceite, cuyos molinos (almazaras o trapiches) sirvieron de modelo para extraer el jugo de la caña. De esta manera, cuando se inició la andadura americana de la caña de azúcar, a partir del segundo viaje de Colón, el vocabulario azucarero que se trasladó al Nuevo Mundo ya estaba configurado, conservándose prácticamente inalterado durante toda la época colonial (2014, p. 19).

Os autores acrescentam que o desenvolvimento da indústria açucareira, na zona do Caribe, converteu as Antilhas e depois a Nova Espanha nos enclaves por excelência da produção açucareira no Novo Mundo. Deste modo, antes de o primeiro engenho ser instalado no Brasil, já o modelo açucareiro atlântico tinha chegado ao Caribe. Das Canárias, a produção açucareira foi transplantada para a ilha Espanhola (atual República Dominicana e Haiti), onde começou a formação da terminologia açucareira americana com o léxico de origem portuguesa. Alguns portuguesismos sofreram alterações fonéticas e gráficas por adaptação à língua espanhola, por exemplo os termos: caldera (de caldeira), templar (de temperar), fornalla (de fornalha), ingenio de agua ou de azúcar (de engenho de água ou de açúcar), pois grande parte do vocabulário do açúcar nas Canárias é adoção e adaptação da terminologia da cultura açucareira transplantada do Português da Madeira, com a mobilidade dos madeirenses, estendendo-se depois à América: Espanhola, Porto Rico, Jamaica, Nicarágua, Costa Rica e ao resto da América hispânica.

Desta terminologia atlântica, destacamos algumas técnicas, instrumentos e profissões específicos da produção açucareira, por exemplo: bagaço (termo antigo, comum a outros produtos agrícolas como a uva e, por extensão semântica, também usado para designar os resíduos da cana-de-açúcar depois de espremida, registado na documentação histórica madeirense e documentado com a mesma forma nas Canárias, onde também encontramos os termos derivados bagaceira, lugar do engenho onde se armazenava o bagaço, e bagaceiro, trabalhador encarregado de recolher o bagaço e de prensá-lo, termos que existiriam e continuam a existir na Madeira, apesar de não estarem atestados na documentação histórica); batedeira ( $b a-$ tidera nas Canárias, instrumento de cobre utilizado para bater o açúcar na tacha, antes de este passar para as formas); calda ou sumo das canas (sumo da cana-deaçúcar extraído no engenho, termos não documentados na Madeira mas que ocor- 
rem nos Açores, em 1588, e caldo no Brasil, em 1628); caldeira (recipiente usado no processo de cozedura do sumo da cana para fazer açúcar); casa de purgar (com a mesma forma na documentação histórica das Canárias, local onde se realizava a última etapa de elaboração do açúcar, que era purgado, separando-o do mel); engenho de água ou engenho de açúcar (ingenio de agua ou ingenio de azúcar nas Canárias, moinho de esmagar a cana-de-açúcar, movido a água); escumas ou espumas(as primeiras impurezas que se retiravam das caldeiras e das tachas, aproveitadas para fazer o chamado açúcar de escumas); escumadeira (espumadera nas Canárias, colher de cobre com furos e cabo comprido, utilizada para retirar a espuma das caldeiras e das tachas, durante a fervura do sumo da cana); forma de açúcar (molde cónico de barro com um furo no vértice, usado para fazer pães de açúcar e para purgar o açúcar); moenda (molienda nas Canárias, com especialização da palavra na terminologia açucareira, ato de moer a cana, quantidade de cana que se mói e tempo durante o qual se fabrica açúcar); raminhol, reminhol ou rominhol (recipiente de cobre empregado para retirar as espumas do sumo da cana fervente e para transferi-lo entre caldeiras e tachas), nas Canárias remillón, remiñol ou reminón também será portuguesismo de reminhol (CoRrales; CoRBELla, 2012, p. 94); tacha (recipiente de cobre usado no processo de concentração do mel, onde se acabava de cozer o melado e se dava ponto ao açúcar). O termo tacha ou tacho ainda hoje existe na América e, por isso, é classificado, muitas vezes, como americanismo. No entanto, não podemos esquecer que, antes de ser levado para a América, este termo surge na Madeira e nas Canárias, sendo um portuguesismo. $\mathrm{O}$ termo temperar (templar nas Canárias) denomina a elaboração dos açúcares com as diferentes consistências necessárias à sua boa cristalização. Lobo Cabrera (1996) refere o ofício de templador das escumas e rescumas nos engenhos das Canárias, indicando que este trabalho também podia ser executado pelos maestros de azúcar. $O$ vocábulo trapiche (moinho de esmagar a cana-de-açúcar, constituído por uma mó de pedra vertical movida a tração animal) resulta da adaptação da tecnologia mediterrânea do azeite e do vinho à cana-de-açúcar. Na documentação das Canárias consultada, apenas registámos a denominação engenio ou ingenio de bestias, que, embora faça referência à tecnologia primitiva de extração do sumo da cana, já usa o novo termo engenho, associado à inovação técnica renascentista da moenda de dois eixos de madeira horizontais movidos a água, que parece ter surgido pela primeira vez na Madeira, no engenho de Diogo de Teive, estando atestada já em 1452, como "hum emgenho daugua" (Melo, 1972-199o, v. I, p. 8). Contudo, Corrales e Corbella (2010) documentam o termo trapiche como vocábulo canárioamericano: "molino movido por bestias, para moler la caña y obtener el azúcar. Lo mismo en Bol., Col., Cuba, Ec., Guat., Hond., Méx., Nic., Par., Perú, P. Rico y Ven., acrescentando que "es palabra propia del léxico azucarero canario, y ya está documentada en las islas desde 1517, según el DHECan." (2010, p. 1021). Anotam ainda que, na Argentina e no Chile, denomina um moinho para pulverizar minerais. 
Ainda no que diz respeito à tecnologia dos engenhos, Vieira transcreve a descrição de Giulio Landi, datada de 1530, que regista o sistema de fabrico de açúcar na Madeira, com cinco caldeiras agrupadas:

\begin{abstract}
Os lugares onde com enorme atividade e habilidade se fabrica o açúcar estão em grandes herdades, e o processo é o seguinte: primeiramente, depois que as canas cortadas foram levadas para os lugares acima referidos, põem-nas debaixo de uma mó movida a água, a qual triturando e esmagando as canas extrai-lhe todo o suco. Aqui há vasos postos por ordem, para cada um dos quais o suco saído das canas passa um certo tempo em ebulição, depois, passando para os outros vasos, com fogo brando, dão-lhe com habilidade a cozedura, de modo que chegue a espessura tal que, posto depois em formas de barro, possa endurecer. A espuma que se forma ao cozer o açúcar, deita-se em barricas, exceto a que sai da primeira cozedura, porque esta se deita fora; mas a outra, que se conserva, é muito semelhante ao mel (VIEIRA, 1996, p. 68).
\end{abstract}

Vieira (s.d., p. 4) explicita que o conhecido trem jamaicano, por supostamente ter tido aí origem, enquanto sistema de cozimento resultante do desenvolvimento de um mecanismo de fornalha única para alimentar cinco caldeiras, embora não tão apurado, teria sido usado na Madeira e nas Canárias, no século XVI. O autor menciona que, nessa altura, nas Canárias, as caldeiras se reuniam em grupos de três ou cinco, sendo servidas por distintas fornalhas ou apenas por uma. Menciona o engenho de Cristóbal Garcia del Castilho, em Telde (Gran Canária), em que as "fornallas son todas juntas", referindo Lobo Cabrera (200o, p. 110-112). A terminologia dos nomes de profissão específicos da cultura açucareira está associada às técnicas produtivas. Na sua maior parte, estes nomes são formados com os sufixos -eiro (em espanhol -ero) e -dor (com a mesma forma nas Canárias): açucareiro (de açúcar, que parece ser sinónimo de canavieiro, em que temos a palavra açúcar por cana, embora também pudesse denominar o mestre de açúcar); caixeiro (artesão que fazia as caixas de madeira para exportação dos produtos açucareiros, termo não documentado nas Canárias); caldeireiro (de caldeira, em espanhol calderero, o encarregado da cozedura e da limpeza do sumo da cana nas caldeiras ou ainda o trabalhador que fabrica as caldeiras do engenho); canavieiro (de canavial, em espanhol cañaverero, que também surge com a forma reduzida cañavero); confeiteiro e doceiro (formas derivadas respetivamente de confeito e de doce, que parecem ser termos com o mesmo significado para designar o fabricante de conservas e confeitos, em espanhol confitero); escumeiro (de escuma, na documentação das Canárias surge com as formas escumero, espumero e rescumero e designa o trabalhador encarregado de retirar as escumas e rescumas das caldeiras, durante a cozedura do sumo da cana); prenseiro (nas Canárias prensero), derivação direta de prensa, com o sufixo -ero, trabalhador responsável pela extração do sumo restante nas canas, depois de esmagadas na moenda. Embora este termo não tenha sido registado na documentação histórica madeirense, terá existido na 
ilha da Madeira, sendo o nome canário de origem portuguesa, a comprová-lo temos o registo do termo prenseiro no Nordeste do Brasil (Houaiss, 2009). O vocábulo tacheiro (de tacha, nas Canárias tachero) denomina o trabalhador do engenho responsável pela concentração do mel nas tachas e que voltava a cozer o mel que não tinha cristalizado. Os nomes de profissão com o sufixo -dor são idênticos nas duas regiões açucareiras: encaixador (derivado de caixa, de encaixar, encaxador nas Canárias, trabalhador que metia o açúcar nas caixas de madeira para exportação); esbrugador (na Madeira e desburgador, com prótese de $d$-, nas Canárias), trabalhador que prepara as canas para a moenda, a par da forma cortador, trabalhador que corta as canas; lavrador (labrador em espanhol); lealdador (de lealdar, portuguesismo que designa o trabalhador que examina a qualidade do açúcar fabricado nos engenhos); moedor (de moer, nas Canárias moledor), termo que sofre uma especialização no âmbito da produção açucareira, nomeando o trabalhador responsável pela moenda da cana no engenho. Embora, na documentação madeirense, este termo surja registado mais tarde, em relação à primeira atestação nas Canárias, neste arquipélago será uma adaptação da forma portuguesa. Aos termos anteriores, devemos juntar ainda os nomes de profissão purgador e refinador: o primeiro trabalhava na casa de purgar, sendo encarregado de purgar o pão de açúcar, purificando-o com barro nas formas para separar o mel do açúcar cristalizado, e o segundo trabalhava na casa de refinar, voltando a cozer o açúcar com restos de mel para este ficar mais fino e puro.

Além das formas derivadas por sufixação, registámos algumas formas compostas idênticas nas duas regiões açucareiras, que, nas Canárias, são portuguesismos, para designar nomes de profissão específicos da produção açucareira, por exemplo: mestre de açúcar (responsável por todo o processo de transformação do sumo da cana em açúcar cristalizado, maestro de azúcar nas Canárias) e mestre de engenho (maestro de hacer ingenios em espanhol). Trata-se de formas compostas pelo nome de profissão mestre com um complemento nominal de especificação, introduzido pela preposição de, que designam profissões especializadas. É importante referir que a maior parte dos mestres de açúcar e de engenhos que encontramos na documentação histórica das Canárias são madeirenses, pois estes foram os grandes responsáveis pela difusão das técnicas da produção açucareira no Atlântico (Nunes, 2001).

Quadro 1: Técnicas e profissões da produção açucareira na documentação histórica

\begin{tabular}{|l|l|}
\hline MADEIRA & CANÁRIAS \\
\hline Açucareiro (Vereações, 1470-72, p. 23) & \\
\hline Alçaprema (Tombo I, 1462, p. 25) & \\
\hline Almoxarife dos açúquares (Tombo II, 1495, p. 308) & \\
\hline & Bagaçera (ACT VII, 1546, p. 43) \\
\hline & Bagacero (PSU, 1578, p. 274) \\
\hline Bagaço (Vereações, 1496, p. 469) & Bagaço (IAgaete, 1505, p. 17) \\
\hline Batedeira (Testamento, 1535, p. 2) & Batidera (PHG II, 1511, p. 284) \\
\hline Cayxeiro (Contas II, 1509, p. 196) & \\
\hline $\begin{array}{l}\text { Calda e sumo das canas (Açores - Saudades IV, 1588, } \\
\text { p. 211), Caldo (Brasil - História do Brasil, 1628, p. 421) }\end{array}$ & Caldo (Terminología, 1509, p. 87) \\
\hline
\end{tabular}




\begin{tabular}{|c|c|}
\hline MADEIRA & CANÁRIAS \\
\hline Caldeira (Contas II, 1513-14, p. 237) & Caldera (PHG, 1511, p. 285; Ord. G.C., 1531, p. 146) \\
\hline Caldeireiro (Vereações, $1485-86$, p. 173) & Calderero (ACT II, 1508, p. 26) \\
\hline Canaueall (Tombo I, 1466, p. 27) & Cañaverales de azúcar (DatasT I-IV, 1501, p. 66) \\
\hline Canavieiro (Contas II, 1513-14, p. 223) & $\begin{array}{l}\text { Cañaverero e cañavero (EPJRB, 1507, p. 52; Ord. G.C., } \\
\text { 1531, p. 115). }\end{array}$ \\
\hline Casa de purgar (LEstimos, 1494, p. 71) & Casa de purgar (IAgaete, 1494, p. 6o) \\
\hline \multicolumn{2}{|l|}{ Coadoiro (Posturas, 1587, p. 73 ) } \\
\hline Confeiteiro (Vereações, 1485-86, p. 186) & Confitero (EPJRB, 1507, p. 118) \\
\hline \multicolumn{2}{|l|}{ Doceiro (Contas II, 1536, p. 125) } \\
\hline Encaixador (Contas I, 1504-o5, p. 4o) & Encajador (PHG I, 1510, p. 365) \\
\hline \multicolumn{2}{|l|}{ Encaixamento (Tombo IV, 1515, p. 575) } \\
\hline Engenho de água ou de açúcar (Tombo I, 1452, p. 8) & $\begin{array}{l}\text { Ingenio de azucar (RdelSello, 1488, p. 29), Ingenio de } \\
\text { agua (DatasT I-IV, 1505, p. 51) }\end{array}$ \\
\hline Esbrugador (Posturas, 1587, p. 74) & Desburgador e Cortador (ACT II, 1508, p. 9) \\
\hline Escuma (Contas I, 1520, p. 57) & Escuma (EPJRB, 1507, p. 72) \\
\hline Escuma das caldeiras (Contas II, 1513-14, p. 237) & Espuma de calderas (Ord. G.C., 1531, p. 145) \\
\hline Escuma das tachas (Contas II, 1513-14, p. 227) & Espuma de tachas (Ord. G.C., 1531, p. 145) \\
\hline Escumadeira das caldeiras (Testamento, 1535, p. 2) & Espumadera (PHG, 1511, p. 284) \\
\hline Escumeiro (Contas II, 1513-14, p. 229) & Escumero e rescumero (PRF I, 1522, p. 360) \\
\hline Forma (Tombo I, 1452, p. 8) & Forma de açúcar (Ord. G.C., 1531, p. 148) \\
\hline Lealdador (Vereações, 1485-86, p. 145) & Lealdador (ACT I, 1506: 107) \\
\hline Lealdar (Vereações, 1470-72, p. 38) & Lealdar (ACT II, 1508, p. 2) \\
\hline Mestre de açúcar (Vereações, 1470-72, p. 23) & Maestro de azúcar (DatasT I-IV, 1504, p. 56) \\
\hline Mestre de engenho (Vereações, $1485^{-86}$, p. 144) & Maestro de hacer ingenios (DatasT I-IV, 1506, p. 230) \\
\hline Moedor (Açúcar, 1655, p. 331) & Moledor (IAgaete, 1505 , p. 25) \\
\hline Moemda (Tombo I, 1461, p. 16) & Molienda (DatasT I, 1504, p. 96) \\
\hline \multicolumn{2}{|l|}{ Panelas (Contas I, 1523, p. 95) } \\
\hline & Prensero (PHG II, 1510, p. 119) \\
\hline Purgador (Tombo III, 1501, p. 411) & Purgador (ACT II, 1510, p. 57) \\
\hline Purgar (Tombo I, 1483, p. 133) & Purgar (ACT II, 1508, p. 2) \\
\hline Raminhois (Testamento, 1535, p. 2) & Remillones (PHG, 1511, p. 284) \\
\hline Refinador (Contas II, 1509, p. 23) & Refinador (PHG, 1511, p. 225) \\
\hline Tacha (Contas II, 1513-14, p. 227) & Tacha (PHG, 1511, p. 284) \\
\hline Tacheyro (Contas II, 1509, p. 182) & Tachero (PAG, 1521, p. 292) \\
\hline Temperar (Vereações, $1481-82$, p. 85) & Templar (ACT II, 1510, p. 55) \\
\hline Trapicha de bestas (Tombo I, 1468, p. 44-45) & $\begin{array}{l}\text { Ingenio de bestias (DatasT I-IV, 1502, p. 59), trapiche } \\
\text { (DHECan, } 1517 \text { apud TLCA Corrales y Corbella, 2010, } \\
\text { p. 1021) }\end{array}$ \\
\hline
\end{tabular}

Elaboração própria

\section{Qualidades de açúcar e outros produtos açucareiros}

As denominações das qualidades de açúcar e de meles são muito importantes na terminologia da manufatura açucareira, uma vez que os produtos e subprodutos desta atividade apresentam várias qualidades, conforme a matéria-prima utilizada, o grau de elaboração e o seu estado, o que origina uma grande variedade de designações, sobretudo na Madeira, associadas ao valor comercial.

No fabrico do açúcar, o pão de açúcar era dividido em partes: o açúcar branco (azúcar blanco em espanhol, o da parte superior da forma, designada cara), o do meio ou açúcar mascavado e o da ponta ou vértice da forma com restos de mel, denominado cogulo. Na documentação das Canárias, registámos os nomes $\operatorname{cog} u$ - 
cho e pies, com adaptação à língua espanhola, para designar este açúcar de inferior qualidade. Os termos escuma e rescuma, com as mesmas formas nas Canárias; $\boldsymbol{m e l}$ (proveniente do mellado, termo documentado na Madeira para o sumo da cana concentrado, antes do ponto de cristalização do açúcar) e remel (miel e remiel em espanhol) designam os primeiros subprodutos do açúcar. Quanto ao vocábulo netas (forma popular do lat. nitidu-, "limpo, claro"), atestado na documentação histórica da Madeira em 1587, trata-se das espumas mais claras e finas ou escumas das tachas (1514), documentadas no Brasil com a forma nettas em Antonil (1711), que eram retiradas das tachas de concentração do açúcar (cf. Nunes, 2003a, p. 423). Nas Canárias, encontramos as formas nietas, netos (1553 apud VIÑa BRITo, 2008) e netas (LA PALMA, 1557 apud ViÑa Brito, 2008), que embora sejam anteriores à atestação madeirense, serão importações e, no caso de nietas, adaptação do português da ilha da Madeira.

O termo panela ou açúcar de panela é igualmente um portuguesismo da Madeira nas Canárias, com as formas paneles, azúcar de panela e panela, designando um açúcar de inferior qualidade, que não era purgado, feito a partir do mel ou do remel, cristalizado num recipiente denominado panela, que, na Madeira, aparece na documentação também como medida e embalagem para exportar açúcar mascabado e conservas. A palavra rapadura (forma derivada de rapar) é também um portuguesismo que, na documentação das Canárias, surge com a forma portuguesa para nomear o subproduto do açúcar resultante das crostas de açúcar caramelizadas, que são rapadas das tachas de concentração do sumo da cana para fazer o açúcar.

Os produtos derivados do açúcar são as conservas e os confeitos (conserva/conserba, confitura e confite, nas Canárias), que também terão influência das denominações portuguesas. As conservas eram igualmente designadas fruta de açúcar na Madeira e nas Canárias, sendo claramente um portuguesismo. As conservas de fruta foram muito variadas, sobretudo na Madeira: conserva de abóbora (conserva de calabacete, nas Canárias), conserva de peras (na Madeira e nas Canárias), diacidrão (conserva de diacitrón nas Canárias), etc.. Outro produto açucareiro importante era o alfenim (doce feito de açúcar manipulado para ficar muito branco, em forma de figuras), cuja primeira atestação registámos em 1469, na documentação histórica madeirense consultada (Melo, 1972-199o, vol. I p. 48). Viña Brito (2008, p. 122), para as Canárias, refere a primeira ocorrência do vocábulo em 1523, com a forma alfenique, entre outros doces, nas Ordenanzas de Tenerife que zelam pela qualidade dos produtos açucareiros, incluindo as conservas e confituras. $\mathrm{O}$ mesmo termo é registado também com a forma alfinique, na documentação com o mesmo nome datada de 1540 .

Quadro 2: Qualidades de açúcar e outros produtos açucareiros

\begin{tabular}{|l|l|}
\hline MADEIRA & CANÁRIAS \\
\hline Açúcar (Tombo I, 1452, p. 7) & Azúcar (RdelSello, 1489, p. 30) \\
\hline Açúcar baixo e ruim (Contas II, 1513-14, p. 240) & Azúcar malo (ACT I, 1507, p. 173) \\
\hline
\end{tabular}




\begin{tabular}{|c|c|}
\hline MADEIRA & CANÁRIAS \\
\hline \multicolumn{2}{|l|}{ Açúcar baixo mascavado (Contas II, 1513-14, p. 229) } \\
\hline \multicolumn{2}{|l|}{$\begin{array}{l}\text { Açúcar baixo somenos mascavado (Contas II, 1513-14, } \\
\text { p. 229) }\end{array}$} \\
\hline Açúcar branco (Tombo I, 1466, p. 27) & Azúcar blanco (ACT I, 1504, p. 72) \\
\hline Açúcar branco bom (Contas I, 1504-05, p. 39) & Azúcar bueno blanco (ACT I, 1507, p. 154) \\
\hline \multicolumn{2}{|l|}{$\begin{array}{l}\text { Açúcar branco de uma cozedura (Contas I, 1522-23, } \\
\text { p. 113) }\end{array}$} \\
\hline \multicolumn{2}{|l|}{ Açúcar candi (Tombo III, 1498, p. 378) } \\
\hline \multicolumn{2}{|l|}{ Açúcar de cara (Tombo I, 1466, p. 27) } \\
\hline Açúcar de cogulo (Tombo I, 1466, p. 27) & Cugacho e cogucho (ACT II, 1509, p. 33) \\
\hline \multicolumn{2}{|l|}{ Açúcar de duas cozeduras (Tombo I, 1469, p. 48) } \\
\hline Açúcar de escumas (Tombo III, 1501, p. 412) & Azúcar de espumas (ACT II, 1508, p. 24) \\
\hline \multicolumn{2}{|l|}{ Açúcar de mel (Contas I, 1520, p. 55) } \\
\hline \multicolumn{2}{|l|}{ Açucar de mel mascavado (Contas I, 1524, p. 136) } \\
\hline \multicolumn{2}{|l|}{ Açucar de mel velho (Contas II, 1517, p. 99) } \\
\hline $\begin{array}{l}\text { Açucar de panella (Tombo I, 1452, p. 8), Panelas (Con- } \\
\text { tas I, 1523, p. 95), Panellas (Cartas, 165o, p. 181) }\end{array}$ & $\begin{array}{l}\text { Paneles (DatasT I-IV, 1508, p. 24), Azúcar de panela } \\
\text { (ACT II, 1508, p. 24), Panela (ACT II, 1509, p. 33), Azú- } \\
\text { car de panela (DatasT I-IV, 1509, p. 33) }\end{array}$ \\
\hline \multicolumn{2}{|l|}{ Açucar de refugo (Contas I, 1504-05, p. 40) } \\
\hline \multicolumn{2}{|l|}{ Açucar de retame (Contas I, 1504-05, p. 41) } \\
\hline Açucar fino (Contas II, 1537, p. 173) & Azúcar fino (RdelSello, 1513, p. 202) \\
\hline Açucar mascavado (Contas I, 1520, p. 59) & Azúcar mascabado (PHG, 1510, p. 114) \\
\hline Açucar refinado (Tombo I, 1469, p. 48) & Azúcar refinado (PHG, 1511, p. 227) \\
\hline \multicolumn{2}{|l|}{ Açucar refinado de mel (Contas I, 1523: 96) } \\
\hline \multicolumn{2}{|l|}{ Açucar refinado fino (Contas I, 1504-05, p. 39) } \\
\hline \multicolumn{2}{|l|}{ Açúcar rosado de escumas (Contas II, 1536, p. 123) } \\
\hline \multicolumn{2}{|l|}{ Açúcar somenos (Tombo I, 1469, p. 48) } \\
\hline \multicolumn{2}{|l|}{ Açúcar velho (Contas II, 1509-11, p. 15 > ) } \\
\hline Alfenim (Tombo I, 1469, p. 48) & $\begin{array}{l}\text { Alfenique (Ord. T., } 1523 \text { apud VIÑA BRITO, 2008, p. } \\
\text { 122), Alfinique (Ord. T., 1540, p. 105) }\end{array}$ \\
\hline \multicolumn{2}{|l|}{ Casca de cidra (Contas I, 1504-05, p. 31) } \\
\hline \multirow[t]{2}{*}{ Confeito (Tombo I, 1469, p. 48) } & Confite (RdelSello, 1496, p. 84) \\
\hline & Confitura (Ord. G.C., 1531, p. 98) \\
\hline Conserva (Tombo I, 1469, p. 48 ) & Conserva (RdelSello, 1489, p. 32) \\
\hline Conserva de abóbora (Contas I, 1504-05, p. 31) & $\begin{array}{l}\text { Calabaçate (Ord. T., } 1523 \text { apud VIÑA BRITO, 2008, p. } \\
\text { 127), Conserba de calabacete (Ord. G.C., 1531, p. 99) }\end{array}$ \\
\hline \multicolumn{2}{|l|}{ Conserva de açúcar branco (Contas I, 1523, p. 92) } \\
\hline \multicolumn{2}{|l|}{ Conserva de açúcar de mel (Contas II, 1513-14, p. 227) } \\
\hline \multicolumn{2}{|l|}{ Conserva de escumas (Contas I, 1523, p. 89) } \\
\hline Conserva de marmelada (Contas II, 1517, p. 101) & \\
\hline Conserva de pera parda (Contas I, 1504-05, p. 31) & Conserva de pera (Ord. G.C., 1531, p. 99) \\
\hline Conserva de pessego (Contas I, 1504-05, p. 31) & \\
\hline Conserva de rescumas (Contas I, 1523, p. 91) & \\
\hline Diacidrão bom (Contas I, 1504-05, p. 31) & Conserva de diaçitrón (ACT V, 1527, p. 174) \\
\hline Escuma quebrada (Contas II, 1513-14, p. 241) & Escuma quebrada (PHG, 1511, p. 263) \\
\hline Escuma velha (Contas I, 1524, p. 138) & \\
\hline Fruta de açúcar (Tombo II, 1490, p. 241) & Fruta de azúcar (ACT V, 1527, p. 174) \\
\hline Fruta de açúcar branco (Contas I , 1523, p. 92) & \\
\hline Fruta de escumas (Contas I, 1523, p. 89) & \\
\hline Fruta de mascavado (Contas II, 1513-14, p. 228) & \\
\hline Fruta de mel (Contas I, 1523, p. 89) & \\
\hline Fruta em conserva (Contas II, 1537, p. 175) & \\
\hline Fruta seca de escumas (Contas II, 1536, p. 123) & \\
\hline Fruta seca de mel (Contas II, 1513-14, p. 227) & \\
\hline Masapões (CEF, 1669, p. 257) & Maçapanes (Ord. T., 1523 apud VIÑA BRITO, 2008) \\
\hline Mel (Tombo I, 1466, p. 27) & Miel (ACT IV, 1523, p. 185) \\
\hline Melles dos açuquares (Tombo I, 147o, p. 49) & Myeles de los açúcares (Ord. G.C., 1531, p. 147) \\
\hline & Myeles de las espumas (Ord. G.C., 1531, p. 147) \\
\hline Mel mascavado (Contas I, 1520, p. 61) & \\
\hline
\end{tabular}




\begin{tabular}{|l|l|}
\hline MADEIRA & CANÁRIAS \\
\hline Mel velho (Contas I, 1523, p. 96) & \\
\hline Mellado (Tombo II, 1490, p. 230) & Melaza (EPJRB, 1508, p. 131) \\
\hline & Melcochas (ACT IV, 1523, p. 185) \\
\hline & Melcochas de miel (ACT IV, 1523, p. 185) \\
\hline Netas (Posturas, 1587, p. 74) & $\begin{array}{l}\text { Nietas, netos (1553 apud VIÑA BRITO, 2008), netas } \\
\text { (LA PALMA, 1557 apud VIÑA BRITO, 2008) }\end{array}$ \\
\hline Pão de açúcar (Vereações, 1481-82, p. 146) & Pan de azúcar (ACT I, 1507, p. 156) \\
\hline Pão de açúcar branco (Tombo V, 1550, p. 120) & Azúcar blanco en panes (PRF I, 1520, p. 166) \\
\hline Pão de açúcar de mel (Contas II, 1513-14, p. 242) & \\
\hline Pão de escumas (Contas II, 1517, p. 108) & \\
\hline Pão de marmelada (Contas I, 1523, p. 92) & \\
\hline Pão pequeno de açúcar (Contas II, 1509, p. 197) & \\
\hline $\begin{array}{l}\text { Pão pequeno de açúcar refinado (Contas II, 1517, p. } \\
\text { 93) }\end{array}$ & \\
\hline & Pie (Ord. G.C., 1531, p. 147) \\
\hline Rapadura (Contas I, 1523: 95) & Rapadura (Ord. G.C., 1531, p. 145) \\
\hline Remel (Vereações, 1470-72, p. 5) & Remiel (RdelSello, 1514: 209) \\
\hline Rescuma (Contas I, 1520, p. 58) & Rescuma (PRF I, 1520: 162) \\
\hline Rescuma quebrada (Contas I, 1523, p. 97) & \\
\hline
\end{tabular}

Elaboração própria

A sistematização dos dados recolhidos na documentação histórica consultada da Madeira (incluindo os Açores e o Brasil) e das Canárias para os séculos XV e XVI, apresentada nos quadros 1 e 2, com o registo da primeira atestação dos termos, mostra-nos a grande similaridade terminológica entre as duas áreas açucareiras. Porém, observando-se o quadro 2, podemos constatar uma maior especificidade denominativa dos (sub)produtos açucareiros na Madeira, tornando a sua listagem mais extensa.

A transplantação da cultura açucareira da Madeira para as Canárias, através dos madeirenses experimentados no cultivo da cana e na fabricação do açúcar, explica a existência de muitos portuguesismos da terminologia do açúcar no arquipélago, tal como muitos outros vocábulos de outras áreas de atividade (PÉrEZ VIDAL, 1991). Esta herança açucareira da ilha da Madeira ainda hoje explica porque é que as Canárias foram denominadas "islas del azúcar", sobretudo a ilha de La Palma, onde a presença madeirense terá sido mais intensa. Como escreve Viña Brito (2008, p. 113), "Canarias son grandes consumidores de azúcar y los palmeros son los más golosos”. A tradição do passado doce ainda está muito presente na ilha de La Palma, designadamente em palavras de origem portuguesa, da Madeira, como: escuma, escumero, mascabado, netas, panela e rapadura, que são características do Espanhol Atlântico das Canárias. 


\section{A atual terminologia açucareira do Atlântico: Madeira, Canárias, Cabo Verde, S. Tomé e Príncipe, Brasil, Colômbia e Venezuela}

Para a recolha da atual terminologia açucareira do Atlântico, elaborámos questionários linguístico-etnográficos sobre a cultura açucareira na ilha da Madeira, realizando os inquéritos em 1998-1999. Mais tarde, deslocámo-nos às Canárias, em 2005, onde fizemos a recolha da atual terminologia açucareira das ilhas de Gran Canaria (Arucas e Telde) e de La Palma (Los Llanos de Aridane e Los Sauces). De igual modo, aplicámos o questionário em Cabo Verde (nas ilhas de Santiago e de Santo Antão) e em S. Tomé e Príncipe (ilha de S. Tomé), depois de adaptado à realidade artesanal e rudimentar da produção açucareira nestes países. Estendemos este estudo ao Brasil, em 2006, também com a devida adaptação à sua realidade produtiva, acrescentando questões relativas ao alfenim e à rapadura, tendo recolhido dados nos Estados da Paraíba, Pernambuco, Baía, Minas Gerais, Santa Catarina e Rio Grande do Sul. No que diz respeito ao alargamento deste estudo à Colômbia e à Venezuela, resultou do projeto internacional denominado "Terminologia Açucareira Ibero-Americana”, com a participação de um investigador da Colômbia e de uma investigadora da Venezuela (NunEs, 2006b). Os questionários são constituídos por duas grandes partes: o cultivo da cana-de-açúcar e o fabrico de produtos açucareiros (mel, açúcar, aguardente/rum/grogue/cachaça, alfenim e rapadura). Os informantes inquiridos foram agricultores e trabalhadores/donos de engenhos e de trapiches.

Esta recolha de dados permite conhecer alguns termos da antiga produção açucareira madeirense presentes, ainda hoje, no vocabulário do açúcar das Canárias, assim como outros portuguesismos. Por exemplo, na ilha de La Palma, mais precisamente em Los Llanos de Aridane, no cultivo e colheita da cana-de-açúcar, registámos o termo de origem portuguesa gallofa (galhofa, "brincadeira alegre"), quando um informante mencionou o conjunto de pessoas que se reúnem para o corte da cana (NunEs, 2006a). Assim, no contexto da cultura açucareira, a palavra gallofa surge como unidade terminológica, sem perder o seu significado corrente, pois quando se reúne um grupo de pessoas, mesmo quando é para trabalhar, há sempre alegria.

Do confronto entre a terminologia açucareira histórica e a atual, podemos constatar que a principal mudança terminológica ocorrida, no mundo atlântico, diz respeito sobretudo ao surgimento do termo guarapo, guarapa ou garapa, atualmente comum à Madeira, às Canárias, ao Brasil e à América espanhola, para designar o sumo da cana-de-açúcar extraído nos engenhos ou fábricas para fazer o mel e a aguardente ou rum, mas também o alfenim, a rapadura e o açúcar na América Latina. Este termo terá surgido e sido difundido a partir das ilhas do Caribe para toda a América Latina, associado aos escravos africanos que trabalhavam na manufatura do açúcar, sendo a sua origem controversa. A primeira atestação conhecida do termo guarapo surge em Santo Domingo, em 1620, num texto de Tirso 
de Molina, e depois no Brasil, a partir de 1643, onde teria adquirido a forma garapa. Esta informação constitui um argumento a favor da origem africana da palavra. No entanto, poderá ser um americanismo, por influência das línguas indígenas americanas, do guarani, do tupi ou ainda uma forma do quíchua. Esta é a hipótese considerada mais plausível para Corrales e Corbella (2010, p. 557-559), depois de fazer uma análise e síntese de toda a documentação conhecida onde este vocábulo ocorre, assim como das diferentes hipóteses levantadas por vários lexicógrafos.

Após a exclusão das hipóteses de origem árabe e greco-latina (de grappe, 'uva') do termo e, apesar da plausibilidade de ser uma forma americana ou afroamericana, surgiu a possibilidade de poder ser um vocábulo de origem guanche ou guanchismo das Canárias. Esta hipótese surgiu ao fazermos entrevistas sobre a terminologia da atual produção açucareira, quando um informante, em Arucas (Gran Canária), afirmou: "Al moler la caña, sale el jugo de la caña, que es lo que se llama guarapo. Guarapo y bagazo yo sempre lo hay conocido como de aquí de Canarias" (Nunes, 2012, p. 232), o que associámos ao facto de o nome guarapo ser muito antigo nas Canárias, sobretudo na ilha La Gomera, denominando o sumo extraído da palma, chamada palmera guarapera, com que se faz o mel de palma e, por extensão semântica, guarapo designa também este licor feito da seiva fermentada da referida palmeira, tradição que parece ter origem na época indígena. Como o fabrico do mel e do rum também implicam um processo de extração e, respetivamente, de cozedura e de fermentação do sumo da cana, seria natural que, por analogia, tivesse passado a denominar também o sumo da cana-de-açúcar. Além disso, sabemos que o léxico canário-americano adotou e recriou palavras de base portuguesa, castelhana e aborígene, além da contribuição afro-americana, originando uma continuidade terminológica entre os dois lados do Atlântico. Nesse sentido, embora não registado na documentação histórica das Canárias, tal como outros termos não atestados mas que sabemos que existiam, poderá ser um vocábulo de torna-viagem. Teria sido levado para a América, onde se teria generalizado, passando a fazer concorrência aos termos sumo e caldo de cana, voltando mais tarde à Europa (Madeira e Canárias).

O termo garapa só aparece na documentação madeirense a partir de finais do século XIX, associado aos emigrantes de torna-viagem das Guianas, para onde tinham migrado para trabalhar na cultura açucareira, bem como à importação de cachaça (aguardente) do Brasil, tornando-se um nome técnico para denominar o sumo da cana extraído nos engenhos. Nos inquéritos linguístico-etnográficos realizados na ilha da Madeira, alguns informantes do concelho de Câmara de Lobos e um da Calheta indicaram o termo camuga ou camua como palavra antiga para designar a garapa. Pestana (1970, p. 17) averba camua como o mesmo que aguardente camua, "a aguardente da cabeça da destilação" e "aguardente das borras". Um dos inquiridos usa o nome melique das canas como sinónimo de sumo da cana ou garapa. No concelho da Ponta do Sol, onde há uma grande percentagem de emigrantes venezuelanos de torna-viagem, os cultivadores de cana-de-açúcar entrevistados referiram as palavras guarapo (sumo da cana), machete (instrumento utili- 
zado para cortar a cana, uma espécie de catana) e trapiche (engenho, lugar onde a cana é transformada). Depois de questionados sobre estes termos, disseram têlos conhecido na Venezuela.

Como dito anteriormente, o projeto de investigação internacional "Terminologia Açucareira Ibero-Americana" permitiu-nos trabalhar em conjunto com investigadores da América Latina, nomeadamente da Colômbia (Carlos Arturo Montoya Correa da Escuela Interamericana de Bibliotecología de la Universidad de Antioquia) e da Venezuela (Melva Josefina Márquez Rojas da Escuela de Idiomas Modernos de la Universidad de los Andes). O principal objetivo foi comparar a atual terminologia da cana-de-açúcar da Colômbia e do Ocidente da Venezuela com as terminologias açucareiras atuais da Madeira, das Canárias (Gran Canaria e La Palma), de Cabo Verde (ilhas de Santiago e de Santo Antão) e do Brasil (Estados da Paraíba, Pernambuco, Baía, Minas Gerais, Santa Catarina e Rio Grande do Sul), aplicando questionários lexicais adaptados à realidade económica e sociocultural destas regiões ou países.

No quadro 3, o estudo comparativo dos dados recolhidos na Colômbia e na Venezuela com os das outras áreas geográficas confirma que existem muitos termos comuns ou semelhantes, como: alfenim (confeito de açúcar branco), conservado sobretudo na ilha Terceira dos Açores, sendo típico e popular nas festas do Divino Espírito Santo (VIEIRA, 2015). O vocábulo existe também no Nordeste brasileiro para denominar o açúcar mascavo que é manipulado para ficar mais alvo, assim como na Venezuela e na Colômbia, com a forma alfeñique e alfandoque, a par do termo melcocha. Nestes países, a expressão azúcar morena ou morenilla corresponde ao nome açúcar mascavo. Outros termos comuns são: bagaceira e bagacillo (bagacinho que fica no sumo da cana, sendo necessário coá-lo ou retirar as impurezas durante a fervura); $\boldsymbol{b} \boldsymbol{a g} \boldsymbol{a z o}$ (a cana depois de esmagada na moenda); $\boldsymbol{c} \boldsymbol{a}$ chaza (impurezas retiradas do sumo da cana); caldeira (grande recipiente industrial de cozedura do sumo da cana); cana-de-açúcar; clarificação (processo industrial de limpeza do sumo da cana) e clarificar (limpar o sumo da cana); descachazar (retirar a cachaza do sumo da cana); garapa, guarapo ou caldo (sumo da cana extraído no engenho); forno ou fornalha (forno de queima do bagaço para alimentar a caldeira); machete (instrumento utilizado para cortar a cana); $\boldsymbol{m a z a}$ bagaceira (cilindro que esmaga a cana), melaza (subproduto do açúcar); melado (mel concentrado no ponto de rapadura ou panela) e meladura (na Venezuela e na Colômbia, concentração do sumo da cana nos engenhos de açúcar); melcocha (de miel e cocha, particípio irregular de cocer, doce de melado ou mel espesso, geralmente de panela, com o qual se fazem caramelos ou bombones de elaboração artesanal e popular em vários países da América Latina, o mesmo que alfandoque); molienda e molino (engenho de moenda da cana); pontista (puntista em espanhol, trabalhador responsável por dar o ponto de cozedura ao melado); rapadura (açúcar bruto, o mesmo que panela ou papelón na Venezuela, difundiu-se no Brasil e na América espanhola, onde coexiste com a forma castelhana raspadura, de raspar); safra (época de e colheita da cana-de-açúcar); soca (raiz da cana); tacha 
ou tacho (termo conservado em todas as áreas açucareiras estudadas, referindose tanto ao processo tradicional de concentração do mel como ao aparelho de evaporação e concentração em vácuo, no fabrico industrial do mel e do açúcar) e tacheiro (tachero em espanhol, encarregado das tachas na cozedura tradicional do mel e encarregado dos químicos na produção de açúcar, nas centrais açucareiras da América Latina); trapiche e trapicheiro (dono ou encarregado do trapiche); vinhaça (resíduos que ficam no fundo do alambique, no fabrico de aguardente ou rum). A propósito do vocábulo rapadura, no Brasil existem muitas variedades deste produto: rapadura batida, rapadura dura ou quebra-queixo, rapadura serenta (mole), também chamada rapa ou mel de rapa e raspa (do tacho), no Rio Grande do Sul, em S. António da Patrulha, denominando um doce vendido quente nas feiras que consiste em melado batido com amendoim, sendo o seu fazedor designado raspeiro. Na ilha de La Palma (nas Canárias), o termo da antiga terminologia açucareira madeirense foi conservado, designando um doce tradicional de gófio (farinha de cereais torrados com mel de cana, feito em forminhas cónicas, tal como o pão de açúcar que era elaborado em formas de açúcar cónicas), de acordo com Pérez Vidal (1983). A rapadura de gófio é a mais típica, a esta juntam-se amêndoas tostadas, canela e limão. Atualmente, já existem outras rapaduras confecionadas com diferentes ingredientes: açúcar, leite, ovo, café ou coco e chocolate ou baunilha.

Podemos constatar que alguns termos da realidade socioeconómica e cultural da Colômbia e da Venezuela, sobretudo relativos aos processos industriais de fabrico de variedades de açúcar branco em centrais açucareiras, são palavras que não encontramos na Madeira, nas Canárias, em Cabo Verde e em S. Tomé e Príncipe, nem no Brasil, onde recolhemos apenas a terminologia associada à cultura açucareira artesanal e tradicional. Todavia, muitos desses termos eram comuns ao Engenho Hinton da Madeira, que fabricava açúcar branco, através do mesmo processo industrial, por exemplo: azúcar crudo, azúcar lavado, azúcar refino ou refinado, central azucarero, centrífuga, cristales de azúcar, cristalización, miel final ou melaza, mielprimera, miel de purga, meladura, preparación de la caña, secado delazúcar e tablón (cf. NUNES, 2003b).

Na Venezuela e na Colômbia, tal como em outros países da América espanhola onde há cultura açucareira, encontramos ainda os termos aguamiel ou guarapo na Venezuela, assim como aguamiel ou aguapanela na Colômbia, bebida doce feita com água fervida e panela ou papelón, que no Brasil é feita com rapadura. Daí as denominações raspadura, raspadura de panela ou panela, na Colômbia, correspondendo à forma rapadura no Brasil. Na Venezuela, panela é sinónimo de papelón ("panela de jugo de caña"), açúcar bruto com grande quantidade de mel. Na Colômbia, ocorre ainda o antigo termo pan de azúcar, "bloco de azúcar en forma de obus", que denomina o açúcar depois de retirado das formas de barro cónicas. Hoje, este último termo parece designar também um bolo de leite com anis em forma de pão, na Venezuela e na Colômbia. Seguidamente, apresentamos o quadro síntese comparativo da atual terminologia açucareira, nas diferentes áreas geográficas estudadas. 
Quadro 3: Estudo comparativo da atual terminologia açucareira do Atlântico

\begin{tabular}{|c|c|c|c|c|c|}
\hline MADEIRA (E AÇORES) & CANÁRIAS & $\begin{array}{l}\text { CABO VERDE E S. TOMÉ E } \\
\text { PRÍNCIPE }\end{array}$ & BRASIL & VENEZUELA & COLÔMBIA \\
\hline & & & & & Azúcar candi \\
\hline & & & & Azúcar crudo & Azúcar crudo \\
\hline & & & & Azúcar lavado & Azúcar lavado \\
\hline Açúcar mascavado & $\begin{array}{l}\text { Azúcar mascabado, azúcar } \\
\text { morena }\end{array}$ & $\begin{array}{l}\text { Açúcra di terra, (a)çúcra } \\
\text { preta, açúcra de mel }\end{array}$ & $\begin{array}{l}\text { Açúcar mascavo, açúcar } \\
\text { grosso, açucão, açúcar em- } \\
\text { bolado, açúcar bruto, açú- } \\
\text { car esfregado, açúcar batido, } \\
\text { açúcar de panela }\end{array}$ & Azúcar morena ou morenilla & $\begin{array}{l}\text { Azúcar morena, azúcar mas- } \\
\text { cavo ou moscovado, azúcar } \\
\text { rosada }\end{array}$ \\
\hline Açúcar refinado & Açúcar refinado & Açúcar fino & Açúcar refinado & Azúcar refino & Azúcar refinado \\
\hline & & & & $\begin{array}{l}\text { Aguamiel, guarapo ou guara- } \\
\text { pita (bebida feita de panela ou } \\
\text { agua de papelón) }\end{array}$ & $\begin{array}{l}\text { Aguamiel ou aguapanela (be- } \\
\text { bida feita de panela ou agua } \\
\text { de papelón) }\end{array}$ \\
\hline Aguardente, rum & Ron, aguardiente & Grogue & Cachaça & Ron, aguardiente & Ron, aguardiente \\
\hline Alfenim (Açores) & & & Alfenim (Nordeste brasileiro) & $\begin{array}{l}\text { Alfeñique e alfondoque } \\
\text { (massa de açúcar mascavado } \\
\text { que é manipulada) }\end{array}$ & $\begin{array}{l}\text { Alfeñique e alfondoque } \\
\text { (massa de açúcar mascavado } \\
\text { que é manipulada) }\end{array}$ \\
\hline Bagaceira & Bagacera & & & Bagazera & Bagacera \\
\hline Bagacinho & Bagacillo & & & Bagacillo & Bagacillo \\
\hline Bagaço & Bagazo & & & Bagazo & Bagazo \\
\hline Cachaça & Cachaza & & & Cachaza & Cachaza \\
\hline Caldeira & Caldera & & & Caldera & Caldero \\
\hline Cana-de-açúcar, cana doce & Caña de azúcar & Cana (de mel) & $\begin{array}{l}\text { Cana-de-açúcar, cana saca- } \\
\text { rina }\end{array}$ & Caña de azúcar & Caña de azúcar \\
\hline & & & & $\begin{array}{l}\text { Caña arrimada ou arrime de } \\
\text { caña }\end{array}$ & \\
\hline & & & & Cañicultor & \\
\hline & & & & Casa de purga & Casa de purga \\
\hline & & & & Central azucarero & Central azucarero \\
\hline & & & & Centrífuga & Centrífuga \\
\hline Clarificação & Clarificación & & & Clarificación & Clarificación \\
\hline Clarificar & Clarificar & & & Clarificar & Clarificar \\
\hline & & & & Cortero & \\
\hline
\end{tabular}




\begin{tabular}{|c|c|c|c|c|c|}
\hline MADEIRA (E AÇORES) & CANÁRIAS & $\begin{array}{l}\text { CABO VERDE E S. TOMÉ E } \\
\text { PRÍNCIPE }\end{array}$ & BRASIL & VENEZUELA & COLÔMBIA \\
\hline Cristais de açúcar & Cristales de azúcar & & Cristais de açúcar & Cristales de azúcar & Cristales de azúcar \\
\hline Cristalização & Cristalización & & Cristalização & Cristalización & Cristalización \\
\hline & Descachazar & & & & Descachazar \\
\hline Engenho, fábrica & $\begin{array}{l}\text { Fábrica (Gran Canária), trapi- } \\
\text { che (La Palma) }\end{array}$ & $\begin{array}{l}\text { Trapiche (de ferro), trapiche a } \\
\text { motor }\end{array}$ & Engenho, fábrica, usina & Trapiche, ingenio & $\begin{array}{l}\text { Trapiche (de hierro), ingenio } \\
\text { (azucarero), fábrica de azúcar }\end{array}$ \\
\hline Evaporação & & & & Evaporación & Evaporación \\
\hline Fornalha & Horno & Fornaja & Forno & Horno & Horno \\
\hline $\begin{array}{l}\text { Garapa, guarapa, garapo da } \\
\text { cana, guarapo, melique das } \\
\text { canas, sumo da cana, camuga } \\
\text { ou camua }\end{array}$ & Guarapo, caldo & Calda & $\begin{array}{l}\text { Garapa, caldo de cana, gua- } \\
\text { rapo (Rio Grande do Sul) }\end{array}$ & $\begin{array}{l}\text { Guarapo, aguamiel ("jugo de } \\
\text { caña") }\end{array}$ & Guarapo, caldo \\
\hline Machete & Machete & & & Machete & Machete \\
\hline & & Mestre de açúcar & & Maestro de azúcar & Maestro de azúcar \\
\hline & Maza bagacera & & & Maza bagacera & \\
\hline Melaço & Melaza & & Melaço & Melaza, miel final & Melaza, miel final \\
\hline Mel de cana & Melado & Mel & Melado & Melado & Melado \\
\hline & & & Meladura & Meladura & Meladura \\
\hline & Melcocha & & & $\begin{array}{l}\text { Melcocha (caramelos ou } \\
\text { bombones feitos de massa de } \\
\text { acúcar bruto) }\end{array}$ & $\begin{array}{l}\text { Melcocha, Alfandoque (ver } \\
\text { Alfenim) }\end{array}$ \\
\hline & & & & & Miel de purga \\
\hline & & & & Miel primera & Miel primera \\
\hline Moenda & Molienda & & Moenda & Molienda & Molienda \\
\hline & Molino & & & Molino & Molino \\
\hline & & & & Pan de azúcar & Pan de azúcar \\
\hline & & & & Prensa & Prensa \\
\hline & & & & Prensero & Prensero \\
\hline & & & & Preparación de la caña & Preparación de la caña \\
\hline & Puntista & Pontista & & Puntista & Puntista \\
\hline & & & & Purgar & Purgar \\
\hline & & & & Quema & Quema \\
\hline
\end{tabular}




\begin{tabular}{|c|c|c|c|c|c|}
\hline MADEIRA (E AÇORES) & CANÁRIAS & $\begin{array}{l}\text { CABO VERDE E S. TOMÉ E } \\
\text { PRÍNCIPE }\end{array}$ & BRASIL & VENEZUELA & COLÔMBIA \\
\hline & $\begin{array}{l}\text { Rapadura (panela, Venezuela } \\
\text { e Brasil) }\end{array}$ & $\begin{array}{l}\text { Cocorota di mel, cocorota di } \\
\text { açúcra, raspadura de cobre, } \\
\text { raspa, raspadura do tacho, ca- } \\
\text { ramelo (de mel), açúcra di co- } \\
\text { bre, (a)çucrinha }\end{array}$ & $\begin{array}{l}\text { Rapadura, rapadura batida, } \\
\text { rapadura dura ou quebra- } \\
\text { queixo, rapadura serenta } \\
\text { (mole), rapa, mel de rapa ou } \\
\text { raspa (do tacho) }\end{array}$ & $\begin{array}{l}\text { Panela ou papelón ("panela } \\
\text { de jugo de caña") }\end{array}$ & $\begin{array}{l}\text { Raspadura, raspadura de pa- } \\
\text { nela ou panela }\end{array}$ \\
\hline & & Reminhola & Reminhol ou rominhol & Remillón ou remellón & Remillón ou remellón \\
\hline & & & & Resiembra & Resiembra \\
\hline Safra & Zafra & & & Zafra & Zafra \\
\hline & & & & Secado del azúcar & Secado del azúcar \\
\hline Soca & Soca & & & Soca & Soca \\
\hline & & & & Tablón & Tablón \\
\hline $\begin{array}{l}\text { Tacha de cobre, tacha do mel, } \\
\text { tina do mel }\end{array}$ & Tacho & $\begin{array}{l}\text { Tacho (de cobre), tacha, cobre } \\
\text { (di mel), caldeira de mel, pa- } \\
\text { nela }\end{array}$ & $\begin{array}{l}\text { Tacho de melado (Rio Grande } \\
\text { do Sul) }\end{array}$ & Tacho (evaporador de vácuo) & Tacho \\
\hline $\begin{array}{l}\text { Tacheiro, homem do mel, co- } \\
\text { zedor do mel, trabalhador do } \\
\text { mel }\end{array}$ & & $\begin{array}{l}\text { Fazedor di mel, cobreiro, ho- } \\
\text { mem di cobre, fornalheiro, } \\
\text { ponteador de mel, trapi- } \\
\text { cheiro, homem de boca de } \\
\text { tacho }\end{array}$ & $\begin{array}{ll}\text { Tacheiro, raspeiro } & \text { (Rio } \\
\text { Grande do Sul) } & \end{array}$ & Tachero & Tachero \\
\hline & & & & Templa & \\
\hline & & & & Templar & \\
\hline & Trapichero (La Palma) & $\begin{array}{l}\text { Trapicheiro, encarregado de } \\
\text { trapiche, fornalheiro, encar- } \\
\text { regado de fornaja }\end{array}$ & & Trapichero & Trapichero \\
\hline Vinhaça & Vinaza & Azugre & & Vinaza & Vinaza \\
\hline
\end{tabular}

Elaboração própria 
Como podemos verificar, atualmente, há uma grande riqueza e diversidade denominativa com semelhanças e diferenças entre os dois lados do Atlântico. As muitas semelhanças existentes devem-se à origem histórica e ao percurso geográfico das técnicas e dos termos ou "coisas e palavras" da cultura açucareira transplantados, a partir da Madeira e das Canárias, para as outras ilhas atlânticas e para a América espanhola. Posto isto, os madeirenses e os canarienses foram os grandes responsáveis e agentes desta disseminação ou propagação além-fronteiras, que favoreceu a transmissão e conservação do léxico do açúcar, formando uma continuidade cultural atlântica.

Salientamos, a negrito, as semelhanças ou continuidade terminológica entre os dois lados do Atlântico. Apesar das inovações técnicas industriais, que mecanizaram as tarefas da cozedura e da purga do açúcar, conservaram-se muitos termos antigos para denominar novos referentes, por exemplo: casa de purga e purgar (na Venezuela, o lugar onde estão as centrífugas e a operação de centrifugar, que separa o mel do açúcar, nas centrais açucareiras), mestre de açúcar (na Colômbia, nome do operário ou maquinista que dirige o processo de fabrico do açúcar nas centrais açucareiras), tacho e tacheiro (respetivamente para a caldeira de vácuo e para o trabalhador responsável por esta, no fabrico industrial) e trapiche (engenho ou fábrica de rum na ilha de La Palma, nas Canárias, onde ainda se conserva este termo da primitiva produção açucareira madeirense), bem como o termo trapichero (forma derivada do nome trapiche com o sufixo -ero, que denomina o dono do trapiche, tendência conservadora da cultura açucareira palmeira, talvez por ter sido a mais aportuguesada). Na Madeira, atualmente, apenas utilizamos os termos engenho - Engenho da Calheta e Engenho do Porto da Cruz -, que fabricam mel e aguardente, sendo pouco mecanizados, e Fábrica de Mel do Ribeiro Seco, mais industrializada, tal como em Gran Canaria a Fábrica de Rum de Arucas.

Os termos mestre de açúcar e trapiche também foram conservados em Cabo Verde e em S. Tomé e Príncipe. No caso de trapiche, originou as formas: trapichar ("esmagar a cana no trapiche", que ganhou um novo significado pelo movimento rotativo dos animais, por exemplo em Cabo Verde, na ilha de S. Vicente, onde trapichar é "passear na praça da cidade do Mindelo, andando às voltas"); trapicheiro (trabalhador responsável por todo o trabalho de transformação da cana ou pela moenda da cana no trapiche) e trapiche a motor (moinho mecânico de moer a cana a gasóleo). Em Cabo Verde e em S. Tomé e Príncipe, a conservação do termo trapiche deve-se ao facto de aí ter sido preservada a tecnologia mais rudimentar, artesanal e familiar dos moinhos de cana-de-açúcar movidos por animais. Ainda hoje, nestes dois arquipélagos e no interior do Brasil, sobretudo no Nordeste mas também em Minas Gerais, assim como no interior da Venezuela e da Colômbia, nas zonas rurais mais isoladas e mais pobres, encontramos o tradicional trapiche de dois eixos de ferro horizontais ou de três cilindros verticais, movido a manivela ou com animais, para extrair o sumo da cana e fazer ra(s)padura ou panela. Assim, na Venezuela e na Colômbia, ainda existem termos antigos como prensero (na Colômbia, "pessoa que introduz a cana no trapiche para ser esmagada ou 
prensada"), remillón com a variante remellón (utensílio de metal, atravessado por um pau, que se usa nos trapiches rudimentares para descachazar, isto é, retirar as impurezas do sumo da cana durante a fervura) e os termos templa e templar (na Venezuela, "procesar el jugo de la caña de azúcar hasta convertirlo en papelón o panela"). No entanto, este conjunto de termos tradicionais tende a desaparecer face ao abandono das técnicas e das palavras da produção açucareira familiar e artesanal e à mecanização crescente das grandes centrais açucareiras.

Concluímos que as migrações humanas, através dos processos de colonização das ilhas atlânticas e do Novo Mundo, promoveram a transmissão e a conservação das "coisas e palavras" do açúcar, como herança da cultura açucareira no Atlântico. O estudo do léxico do açúcar e do seu percurso histórico e geográfico confirmam a importância das ilhas na construção do mundo Atlântico, sobretudo da Madeira na sua ligação a Cabo Verde, a S. Tomé e Príncipe e ao Brasil, mas também às Canárias, na transplantação e decalque da terminologia açucareira madeirense para a América espanhola. Deste modo, os intercâmbios linguísticos e culturais levaram à adoção e adaptação da terminologia europeia à cultura açucareira do Novo Mundo. Os arquipélagos da Madeira e das Canárias foram e continuam a ser pontes entre os três continentes (Europa, África e América), configurando a continuidade e a unidade cultural atlântica.

\section{Documentação histórica: Madeira, Açores, Brasil e Canárias}

Antonil, A. J. Cultura e opulencia do Brasil por suas drogas e minas. Lisboa, edição fac-similada, 1711.

CEF: Gomes, Eduarda. O convento da encarnação do Funchal: subsídios para a sua história (1660-1777). Funchal: Direção Regional dos Assuntos Culturais, 1995.

Contas I: Costa, J. Pereira da; Pereira, F. Jasmins. Livros de contas da Ilha da Madeira 1504-1537. I - Almoxarifados e Alfândegas. Coimbra: Biblioteca Geral da Universidade de Coimbra, 1985.

Contas II: Costa, José Pereira da; Pereira, Fernando Jasmins. Livros de Contas da Ilha da Madeira 1504-1537. II - Registo da Produção de Açúcar. Funchal: Centro de Estudos de História do Atlântico, 1989.

Vereações: Costa, J. Pereira da. Vereações da Câmara Municipal do Funchal: século XV. Funchal: Centro de Estudos de História do Atlântico, 1995.

Tombo: Melo, L. F. C. de Sousa. Arquivo histórico da Madeira: tombo primeiro do Registo Geral da Câmara Municipal do Funchal. Funchal: Direção Regional dos Assuntos Culturais, 1972-1990.5 v.

Posturas: Posturas que fizerão os offiçiaes do anno de oiteta e sete (1587) - titulo das posturas dos engenhos. Arquivo histórico da Madeira, Funchal, v. I, p. 73-75, 1931. 
LEstimos: RAU, V.; MAcEDo, J. de. Livro dos estimos do ano de 1494. RaU, Virgínia; Macedo, Jorge $O$ açúcar da Madeira nos fins do século XV. Problemas de produção e comércio. Funchal: Junta Geral do Distrito Autónomo do Funchal, 1962. p. 47-98.

Testamento: Testamento de António Teixeira de 1535. A flor do oceano, Funchal, n. 259, p. 2, 7 out. 1865 .

Açúcar: Vieira, Alberto. O açúcar na Madeira: séculos XVII e XVIII. In: Actas: III Colóquio Internacional de História da Madeira. Funchal: Direção Regional dos Assuntos Culturais; Centro de Estudos de História do Atlântico, 1993. p. 325-344.

Cartas: Vieira, Alberto. Cartas de Diogo Fernandes Branco (1649-1652). In: O público e o privado na história da Madeira. Funchal: Centro de Estudos de História do Atlântico, 1996. v. 1, p. 43-262.

Saudades IV: Frutuoso, Gaspar. Livro quarto das saudades da terra (1588-159o). Ponta Delgada: Instituto Cultural de Ponta Delgada, 1981. v. 2.

História do Brasil: SAlvador, Frei Vicente do. História do Brasil (150o-1627). São Paulo: Melhoramentos, 1954 .

ACT I: Instituto de Estudios Canarios. Acuerdos del Cabildo de Tenerife 14971507. Edición y estudio de Elías Serra Ráfols. La Laguna: Universidad de La Laguna, 1949 .

ACT II: Instituto de Estudios CANARios. Acuerdos del Cabildo de Tenerife II 15081513. Con un apéndice de documentos sobre el gobierno de la isla hasta 1513. Edición y estudio de Elias Serra Ráfols y Leopoldo de la Rosa. La Laguna: Universidad de La Laguna, 1952.

ACT III: Instituto de Estudios Canarios. Acuerdos del Cabildo de Tenerife III 1514-1518. Con un apéndice de documentos sobre el gobierno de las islas. Edición y estudio de Elías Serra Ráfols y Leopoldo de la Rosa. La Laguna: Universidad de La Laguna, 1965 .

ACT IV: Instituto de Estudios Canarios. Acuerdos del Cabildo de Tenerife IV. 1518-1525. Con dos apéndices de documentos sobre el gobierno de las islas. Edición y estudio de Elías Serra Ráfols y Leopoldo de la Rosa. La Laguna: Universidad de La Laguna, 1970.

ACT V: Instituto de Estudios Canarios. Acuerdos del Cabildo de Tenerife V. 15251533. Con un apéndice de documentos. Edición y estudio de Leopoldo de la Rosa y Manuela Marrero. La Laguna: Universidad de La Laguna, 1986.

ACT VII: Instituto de Estudios Canarios. Acuerdos del Cabildo de Tenerife VII. 1545-1549 Edición y estudio de Manuela Marrero, María Padrón y Benedicta Rivero. La Laguna: : Universidad de La Laguna, 2000.

Azúcares: Viña Brito, Ana. Azúcares, mieles y remieles. In: Viña Brito, Ana; Gambín García, Mariano; Chinea Brito, Carmen Dolores (Coord.). Azúcar: los 
ingenios en la colonización canaria (1487-1525). Tenerife: Museo de Historia y Antropología de Tenerife, 2008. p. 113-131.

RdelSello: Aznar Vallejo, Eduardo. Documentos canarios en el Registro del Sello 1476-1517. La Laguna: Tenerife, 1981.

PHG II: Clavijo Hernández, Fernando. Protocolos de Hernán Guerra (1510-1511). Santa Cruz de Tenerife: Aula de Cultura del Cabildo de Tenerife; Instituto de Estudios Canarios, 1980.

Terminología: CoRrales, Cristóbal; Corbella, Dolores. Terminología azucarera canaria en América: el inventario del ingenio de Hernando Gorjón. In: CoRBELlA, Dolores; ViñA BRITo, Ana. La ruta azucarera Atlántica: historia y documentación. Funchal: Centro de Estudos de História do Atlântico, 2012. p. 80-10o.

IAgaete: Gambín Garcia, Mariano. El ingenio de Agaete: oro dulce en Gran Canaria a Comienzos del siglo XVI. Las cuentas de la hacienda (1503-1504) y otras noticias de la época (1480-1517). Santa Cruz de Tenerife: Oristán e Gociano Editores, 2008. 2 v.

PSU: Gómez Gómez, Miguel Ángel El valle de Guímar en el siglo XVI: protocolos de Sancho Urtarte. Santa Cruz de Tenerife: Ayuntamiento de Guímar y Cabildo de Tenerife, 2000.

PAG: Lobo Cabrera, Manuel. Protocolos de Alonso Gutierrez (1520-1521). Gran Canaria: Instituto de Estudios Canarios, 1979.

EPfRB: Marrero Rodriguez, Manuela. Extractos del Protocolo de fuan Ruiz de Berlanga 1507-1508. La Laguna: Tenerife, 1974.

PRF I: Martinez Galindo, Pedro. Protocolos de Rodrigo Fernández 1520-1526 (primera parte). San Cristóbal de La Laguna: Isla de Tenerife, 1988.

DatasT I: Moreno Fuentes, Francisca. Las datas de Tenerife. (Libro Primero de Datas por Testimonio) [1500-1527]. La Laguna: Instituto de Estudios Canarios, 1992.

Ord.G.C.: Ordenanzas del Concejo de Gran Canaria (1531). Transcripción y Estudio por Francisco Morales Padrón. Gran Canaria: Cabildo Insular de Gran Canaria, 1974 .

Ord. T.: Peraza De Ayala, José. Las ordenanzas de Tenerife y otros estudios para la historia municipal de Canarias. Tenerife: Aula de Cultura de Tenerife, 1976.

PHG I: González Yanes, Emma; Marrero Rodríguez, Manuela. Protocolos de Hernán Guerra I: extractos de los protocolos del escribano Hernán Guerra de San Cristóbal de La Laguna (1508-1510). La Laguna: Instituto de Estudios Canarios, 1958.

DatasT I-IV: Serra Rafols, Elías. Las datas de Tenerife . Libros I a IV de Datas originales. Índices de Agustin Guimera Ravina. La Laguna: Tenerife, 1978. 


\section{Referências}

CARreira, António. Estudos de economia caboverdiana. Lisboa: Imprensa Nacional Casa da Moeda, 1982.

Corrales, Cristóbal; Corbella, Dolores. Tesoro léxico canario-americano. Las Palmas de Gran Canaria: Casa de Colón, 2010. (TLCA)

Díaz Alayón, Carmen; Javier Castillo, Francisco. Notas lingüísticas sobre los Protocolos de Blas Ximón. Revista de Estudios Generales de La Isla de La Palma, Isla de La Palma, n. 4, p. 313-344, 2009.

Frutuoso, Gaspar. Livro primeiro das saudades da terra. Ponta Delgada, s.d.

Houarss, Antonio et al. Dicionário Houaiss da Língua Portuguesa. Rio de Janeiro: Instituto Antônio Houaiss de Lexicografia, 2009.

Lobo Cabrera, Manuel. Azúcar y trabajo en Canarias. In: Malpica Cuello, Antonio. Agua, trabajo y azúcar: actas del Sexto Seminário Internacional sobre la Caña de Azúcar, Motril, 19-23 de septiembre de 1994. Motril: Diputación Provincial de Granada, 1996. p. 223-237.

Lobo Cabrera, Manuel. El ingenio en Canarias. In: Vieira, Alberto. História e Tecnologia do Açúcar. Região Autónoma da Madeira: Centro de Estudos de História do Atlântico, 200o. p. 105-115.

Lopes Filho, João. Cabo Verde: retalhos do quotidiano. Lisboa: Caminho, 1995.

Lopes Filho, João. O corpo e o pão: o vestuário e o regime alimentar caboverdianos. Oeiras: Câmara Municipal de Oeiras, 1997.

Nunes, Naidea Nunes. A terminologia histórica do açúcar nas Ilhas Atlânticas: Madeira e Canárias (séculos XV e XVI). In: MAssa, Françoise (Ed.). Les îles Atlantiques: realités et imaginaire. Rennes: Université Haute Bretagne Rennes 2, 2001, p. 139-161.

Nunes, Naidea Nunes. O açúcar de cana na ilha da Madeira: terminologia e tecnologia históricas e atuais da cultura açucareira do Mediterrâneo ao Atlântico. Tese (Doutorado em Linguística Românica) - Universidade da Madeira, 2002.

Nunes, Naidea Nunes. Palavras doces: terminologia e tecnologia históricas e atuais da cultura açucareira do Mediterrâneo ao Atlântico. Governo Regional da Madeira: Centro de Estudos de História do Atlântico, 2003a.

Nunes, Naidea Nunes. O património linguístico-histórico-cultural do Engenho Hinton. In: SousA, Élvio (Coord.). Património Cultural da Região Autónoma da Madeira: Livro Branco. Gaula: Archais, 2003b, p. 94-102.

Nunes, Naidea Nunes. Madeirensismos na terminologia açucareira atual das Canárias. Estudios Portugueses, Salamanca, n. 6, p. 45-56, 2006 a. 
Nunes, Naidea Nunes. A terminologia ibero-americana do açúcar de cana: diálogo de línguas e culturas. In: EstopÀ, Rosa; CABré, María Teresa; Soriano, Carles Tebé (Ed.). La terminologia en el siglo xxi: contribución a la cultura de la paz, la diversidad y la sostenibilidad. Barcelona: Institut Universitari de Linguística Aplicada, Universitat Pompeu Fabra, 2006b, p. 235-244.

Nunes, Naidea Nunes. Outras palavras doces: glossário comparativo da atual terminologia açucareira no Atlântico. Governo Regional da Madeira: Centro de Estudos de História do Atlântico, 2010.

Nunes, Naidea Nunes. A contribuição da linguística para o estudo da rota e da terminologia açucareiras: do Mediterrâneo ao Atlântico. In: CoRbella, Dolores; VIÑA BRITo, Ana. La ruta azucarera Atlántica: historia y documentación. Funchal: Centro de Estudos de História do Atlântico, 2012. p. 214-258.

Peraza De Ayala, José. Las antíguas ordenanzas de la Isla de Tenerife: notas y documentos para la historia de los municipios canarios. La Laguna: Instituto de Estudios Canarios, 1935.

PÉrez Morera, Jesús. El azúcar y su cultura en las Islas Atlánticas. Islas Canarias: 500 Años de La Palma y Flandes (1513-2013), 2013. v. 2.

PÉREZ VIDAL, José. Las Canarias: via de introducción de portuguesismos en América. In: Colóquio de Estudos Etnográficos Dr. José Leite de Vasconcelos, 18 a 23 jun. 1958, Porto. Actas... Porto: Junta de Província do Douro Litoral, 1960. v. 3, p. 1-9.

PÉREz VIDAL, José. Contribución luso-española a la cultura y al léxico azucareros latino-americanos. In: Congresso Luso-Espanhol, 29., 31 mar. a 4 abr. 197o, Lisboa. Atas... Lisboa: Associação Portuguesa para o Progresso das Ciências, 1970. tomo 3, p. 1-12.

Pérez Vidal, José. La rapadura. El Museo Canario, Las Palmas de Gran Canaria, tomo XLIII, p. 51-68, 1983.

PÉRez VIDAL, José. Los portugueses en Canarias: portuguesismos. Gran Canaria: Ediciones del Cabildo Insular de Gran Canaria, 1991.

Pestana, Eduardo Antonino. Ilha da Madeira: estudos madeirenses. Funchal: Câmara Municipal do Funchal, 1970. v. 2.

VieIra, Alberto. O comércio inter-insular nos séculos XV e XVI: Madeira, Açores e Canárias. Funchal: Centro de Estudos de História do Atlântico, 1987.

VieIRA, Alberto. Os escravos no arquipélago da Madeira: séculos XV a XVII. Funchal: Centro de Estudos de História do Atlântico, 1991.

Vieira, Alberto. A rota do açúcar na Madeira. Funchal: Associação dos Refinadores de Açúcar Portugueses, 1996. Título em inglês: The Sugar Route in Madeira. 
Vieira, Alberto. Alfenim da Madeira para o mundo. Funchal: Cadernos de Divulgação do CEHA, n. 8, 2015.

Vieira, Alberto. Canaviais e açúcar no espaço insular atlântico: questões de meio ambiente e técnica. Funchal: Centro de Estudos de História do Atlântico, [s.d.]. Disponível em: http://www.madeira-edu.pt/Portals/31/CEHA/bdigital/ hsugar-sugambiente2.pdf. Acesso em: 30 dez. 2017.

Viña Brito, Ana. Azúcares, mieles y remieles. In: Viña Brito, Ana; Gambín GaRcía, Mariano; Chinea Brito, Carmen Dolores (Coord.). Azúcar: los ingenios en la colonización canaria (1487-1525). Tenerife: Museo de Historia y Antropología de Tenerife, 2008. p. 113-131. (Azúcares)

VIÑA BRITo, Ana. Ordenanzas sobre el azúcar de caña en el siglo XVI: un análisis comparativo. HID, n. 4o, p. 397-425, 2013.

Viña Brito, Ana; Corrales, Cristóbal; Corbella, Dolores. Voces dulces. In: Viña BRITO, Ana et al. Islas y voces del azúcar: Tenerife, La Gomera y La Palma. Documentos para la historia de Canarias XI. Gobierno de Canarias: Archivo Histórico Provincial de Santa Cruz de Tenerife; Archivo Histórico Provincial de Las Palmas de Gran Canaria, 2014. p. 19-41.

Recebido em 14 de março de 2018.

Aprovado em 17 de setembro de 2018.

\section{Resumo/Abstract/Resumen}

O léxico da cultura açucareira na construção do mundo atlântico: Madeira, Canárias, Cabo Verde, S. Tomé e Príncipe, Brasil, Venezuela e Colômbia

\section{Naidea Nunes Nunes}

A ilha da Madeira desempenhou um importante papel no desenvolvimento da produção açucareira, transplantada do Mediterrâneo para o Atlântico, e na transmissão desta cultura às ilhas atlânticas das Canárias, Cabo Verde, S. Tomé e Príncipe e ao Brasil. As Canárias também contribuíram para a expansão desta atividade ao outro lado do Atlântico, nomeadamente às Antilhas espanholas, à Venezuela e à Colômbia. $\mathrm{O}$ açúcar foi um dos primeiros produtos globais no comércio atlântico, promovendo trocas linguísticas e culturais entre as várias áreas açucareiras, sobretudo nas ilhas atlânticas e no novo mundo latino-americano. Por isso, hoje, temos uma terminologia açucareira comum aos dois lados do Atlântico, que importa conhecer, valorizar e salvaguardar.

Palavras-chave: Léxico, Terminologia, Ilhas Atlânticas, Brasil, Venezuela, Colômbia, Cultura Açucareira Ibero-Americana. 
The Lexicon of the Sugar Cane Culture in the Atlantic World Construction: Madeira, Canaries, Cap Vert, S. Tome and Prince, Brazil, Venezuela and Colombia

\section{Naidea Nunes Nunes}

Madeira Island played an important rôle in the development of sugar cane production, transplanting the Mediterranean in the Atlantic, and in the transmission of this culture to the Atlantic islands of the Canary Islands, Cape Verde, S. Tome and Prince and Brazil. The Canaries also transmitted this knowledge, techniques and words, to the other side of the Atlantic Ocean, to the Caribbean Antilles, Venezuela and Colombia. Sugar cane was one of the first global products in Atlantic trade, promoting linguistic and cultural exchanges between the different sugar growing areas, mainly in the Atlantic islands and in the Latin-American new world. That's why today we have one common sugar terminology on both sides of the Atlantic, which is important to know, to valorize and preserve.

Keywords: Lexicon, Terminology, Atlantic Islands, Brazil, Venezuela, Colombia, Ibero-American Sugar Cane Culture.

El léxico de la cultura azucarera en la construcción del mundo atlántico: Madeira, Canarias, Cabo Verde, Santo Tomé y Príncipe, Brasil, Venezuela y Colombia

\section{Naidea Nunes Nunes}

La isla de Madeira desempeñó un importante papel en el desarrollo de la producción azucarera, trasplantada del Mediterráneo al Atlántico, y en la transmisión de esta cultura a las islas atlánticas de Canarias, Cabo Verde, Santo Tomé y Príncipe y Brasil. Las Canarias también contribuyeron a la expansión de esta actividad al otro lado del Atlántico, especialmente a las Antillas españolas, Venezuela y Colombia. El azúcar fue uno de los primeros productos globales en el comercio atlántico, promoviendo intercambios lingüísticos y culturales entre las varias áreas azucareras, sobre todo en las islas atlánticas y en el nuevo mundo latinoamericano. Por eso hoy tenemos una terminología azucarera común a los dos lados del Atlántico, que importa conocer, valorar y salvaguardar.

Palabras clave: Léxico, Terminología, Islas Atlánticas, Brasil, Venezuela, Colombia, Cultura Azucarera Iberoamericana. 